\title{
Erratum: Local vibration characteristics of rotating blades induced by moving rub impact loads
}

\author{
Chaofeng $\mathrm{Li}^{1}$, Houxin $\mathrm{She}^{2}$, Shuhua Yang ${ }^{3}$, Hexing $\mathrm{Yu}^{4}$, Bangchun Wen \\ ${ }_{1,2,4,5}$ School of Mechanical Engineering and Automation, Northeastern University, \\ Shenyang, 110819, China \\ ${ }^{3}$ Shenyang Blower Works Group M\&C Tech. Co. Ltd., Shenyang, 110869, China \\ ${ }^{1}$ Corresponding author \\ E-mail: 1'chaof.li@gmail.com, ${ }^{2}$ houxin_she@sina.com, ${ }^{3}$ shy.yang@126.com,.4yxx.neu@gmail.com, \\ 5bcwem1930@vip.sina.com
}

DOI https://doi.org/10.21595/jve.2018.20365

Check for updates

Copyright $(2018$ JVE International Ltd. This is an open access article distributed under the Creative Commons Attribution License, which permits unrestricted use, distribution, and reproduction in any medium, provided the original work is properly cited.

\section{Publisher's note regarding paper}

Li Chaofeng, She Houxin, Yang Shuhua, Yu Hexing, Wen Bangchun Local vibration characteristics of rotating blades induced by moving rub-impact loads. Journal of Vibroengineering, Vol. 16, Issue 5, 2014, p. 2610-2623.

\section{The description of the correction}

Fig. 1(a) from the Ref. [1] was used, but the reference was not cited in figure title and the copyright was missing in the original article and finally approved (after the acceptance) by the authors.

The revised figure title is as follows:

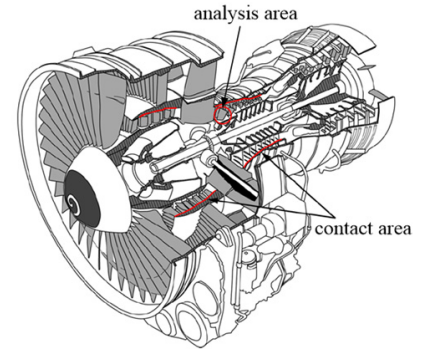

a)

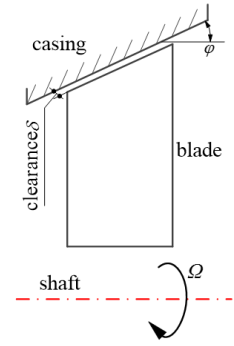

b)

Fig. 1. Schematic of rotating blades force environment: a) Cut-view of an aircraft engine with sensitive contact areas [1] (https://doi.org/10.1115/1.4006446; Copyright (C) 2012 by American Society of Mechanical Engineers); b) Schematic of blade-casing 